\title{
DECONSTRUYENDO EL MAPA CONSERVADOR. SOBRE EL RENACIMIENTO DE LA GEOGRAFÍA EN EL SIGLO XXI
}

\author{
Josep Vicent Boira \\ Departamento de Geografia. Universidad de Valencia \\ Josep.Boira@uv.es
}

\section{RESUMEN}

En la actualidad se observa un renacimiento de la atención por los estudios espaciales. La geografía ha vuelto. Y con ella, los análisis geopolíticos. Pero esta vuelta de la geografía se produce, en algunos casos, sobre la idea del «mapa conservador», un concepto que habla tanto de una ideología como de una aproximación poco crítica al espacio. En este artículo se revisan las bases de esta vuelta de la geografía, se critican las estrategias del mapa conservador desde una perspectiva deconstructivista y se propone una aproximación diferente que permita la vuelta de una geografía más justa y solidaria.

Palabras clave: geografía humana, geopolítica, mapa conservador, deconstrucción, postmodernidad, injusticia

\section{ABSTRACT}

Today there is a renaissance of the attention about space studies. Geography is back and, with it, the geopolitical analysis. But this return to the Geography occurs, in some cases, on the idea of the «conservative map», a concept that talks about an ideology but also about an uncritical approach to that space. In this article we review the basis of this return of the Geography, we criticize conservative map strategies from a deconstructive perspective and we propose a different approach to allow the return of amore fair and solidarity approach.

Key words: human geography, geopolitics, conservative map, deconstruction, postmodernity, unfairness

Fecha de recepción: marzo 2013.

Fecha de aceptación: enero 2014. 
El título de este artículo puede inducir a pensar en una prolongación de los estudios de J.B.Harley y en realidad debe hacerlo aunque matizadamente, no iconográficamente queremos decir. Brian Harley fue el primero en proponer la deconstrucción del mapa (Lladó, 2012) y en señalar la potencia extraordinaria de esta acción para conocer el auténtico significado del mismo y de su envés. No es de extrañar que Harley comenzara un artículo sobre el tema (de 1989, posteriormente compilado como capítulo V en su libro de 2001) con la siguiente frase: «Una mapa nos dice: «Léeme con cuidado, sígueme de cerca y no dudes de mí». Y continúa: «Soy la tierra en la palma de tu mano. Sin mí, estás solo y perdido». Este fragmento procedente de la obra West with the night de Beryl Markham (1942) certifica la importancia del mapa en la sociedad contemporánea.

En la primavera de 2009, Robert D. Kaplan publicó un artículo en la revista Foreign Policy titulado The revenge of Geography (y que en 2012, ha dado pie a un libro con su mismo título que comentaremos más adelante). Su tesis principal es que el olvido reciente de esta disciplina, su desconocimiento, ha llevado a muchos gobernantes a tomar decisiones erróneas. Cierto que «revenge» en inglés se suele traducir por «venganza», pero nos encontramos que etimológicamente (prefijo intensivo re + vengier, del latín vindicare) también es una palabra que podría perfectamente tener sentido en su traducción de «reivindicación», de volver a clamar defensa de algo que ha sido injustamente injuriado, calumniado, condenado... Kaplan aboga por un contenido que se acerca tanto a la primera traducción, pues cita en su ayuda textos y principios de los grandes geopolíticos del siglo XIX y XX, desde Mackinder a Mahan con sus dramáticas consecuencias bélicas y geoestratégicas, como a la segunda, recordándonos que la globalización no ha hecho sino reforzar el papel de los estudios espaciales. En aquel artículo, Kaplan nos daba la receta de nuestros tiempos: volver al mapa, reivindicar aquellos pensadores que mejor conocían el paisaje y actualizar nuestras teorías para adaptarlas a la «vindicación/venganza» de la geografía de hoy en día. Manos a la obra, pues. En aquel artículo de 2009, Kaplan cita a Fernand Braudel (de quien destaca su comprensión del problema medioambiental como motor de procesos históricos), a Alfred Thayer Mahan (de quien elogia su visión naval del equilibrio de fuerzas y el papel fundamental del Pacífico y del Índico, tan de actualidad por el despliegue indio y chino), de Nicholas Spykman (de quien le interesa las formas de controlar al gigante ruso) y sobre todo de Halford J. Mackinder (quien, a ojos de Kaplan ya predijo las dos guerras mundiales del siglo $\mathrm{XX}$ sin haberlas conocido y de quien toma la idea de la subordinación de la historia europea a la de Asia).

Pero Kaplan no sólo reivindica la naturaleza sabia de la geografía y de la geopolítica, sino que propone una más arriesgada tesis que mezcla ideas y dominio territorial: «las luchas más profundas de la Humanidad no se producen por las ideas, sino por el control del territorio». En una magnífica frase, Kaplan señala: of course, ideas matter, and they span Geography. And yet there is a certain geographic logic to where certain ideas take hold. La lógica geográfica de las ideas, las ideas que abarcan a la geografía están de actualidad... En España, conocemos bien esta relación. El diseño de una red de alta velocidad se ha realizado tomando como base una visión radial de las comunicaciones; el agua y su reparto se esgrimen como fuerzas de choque de la contienda partidista; los territorios y sus rasgos propios son enfrentados y a veces ridiculizados con finalidades inconfesables; la estructura administrativa de municipios y provincias procede del siglo XIX y nadie se atreve a cambiarla por respeto 
el statu-quo, mientras presidentes de gobierno buscan en las Azores alterar de raíz viejas y funcionales querencias geopolíticas y gobernantes regionales se inventan ejes de prosperidad artificiales olvidando intereses vitales que han construido, literalmente, siglos de geohistoria. La complejidad del gobierno del territorio se traduce, en nuestro país, en palabras vanas y en ninguna estructura real de representación, cogestión y cooperación. Vuelve la geografía, a veces vuelve explosiva y, en España, desorganizada.

Cuenta Nicholas Lemann (2001) que, a finales de la segunda guerra mundial, la mayoría de universidades de la Ivy League, la prestigiosa red de centros académicos norteamericanos, abolieron los departamentos de geografía, «but Geography is back», como veremos en las siguientes páginas. Aunque esta vuelta de la geografía se ha producido con una especialísima característica: ha vuelto, en muchos lugares, materializada en un mapa muy particular, el «mapa conservador», la particular forma en la que el pensamiento neoliberal ha tratado de no perder el tren de la postmodernidad y del cambio social.

\section{EL RENACIMIENTO DE LA GEOGRAFÍA Y EL MAPA CONSERVADOR}

Hoy es habitual encontrar en nuestro entorno el que denominamos el «mapa conservador». Pero este concepto va más allá de una referencia concreta y puntual al objeto material del proceso cartográfico, es decir, al mapa. Cuando hablamos del «mapa conservador» nos referimos tanto a ese objeto en sí mismo como a la visión direccional, tendencial, al marco narrativo (territorial, espacial) que domina en nuestra sociedad sobre ella misma y sobre los procesos que la envuelven. El mapa es, en sí mismo, un objeto (un fin por tanto), pero es también un medio para orientarse. Ambas nociones están contenidas en la cita inicial de este artículo, reproducida por Harley (2001) y extraída del libro de memorias de Beryl Markham, West with the night, la primera mujer piloto que en solitario cruzó el Atlántico. Este doble sentido, de producto final y de proceso, es el que vamos a tomar aquí. Algo nos diferencia de la posición de Harley. Para el fin de este artículo el concepto «mapa» es algo más que un producto iconográfico (tras el que se vislumbra el poder, como dice Harley). No analizaremos tanto el «mapa» como signo, sino la retórica de contenido geográfico (o su ausencia) en España, el «mapa» como hoja de ruta, como materialización del giro espacial pronosticado, entre otros, por Edward Soja. Por resumir nuestra posición aprovechando un artículo reciente que compara dos aproximaciones (la de Harley y la de Farinelli, Lladó, 2012), estaríamos más cerca de los análisis de Farinelli que de los de Harley, pues el primero profundiza más en el papel del mapa (en general) como elemento estructurador del mundo (de aquí la importancia por su lucha y el valor de quien lo posee) y como instrumento legitimador de políticas mediante el proceso de naturalización de su representación.

En cuanto al adjetivo «conservador», éste no debe entenderse, sólo, como una referencia a la ideología clásica del ala neoliberal de la sociedad occidental, sino también como una referencia a una actitud, a una forma de abordar el análisis de la realidad territorial, económica y espacial excesivamente cautelosa, poco comprometida, poco audaz, escasamente arriesgada, pobremente innovadora.

El «mapa conservador» es tanto un mapa ideológico como una actitud ciudadana, académica, científica incluso. El «mapa conservador» es tanto la manifestación de una ideología, como el reflejo de una actitud. Este «mapa conservador» se observa, de hecho y nunca mejor 
dicho, en la ciencia geográfica que, a nuestro modo de ver, debería ser la primera en dejar hacer oír su voz en los grandes debates actuales. ¡Justo cuando la geografía humana actual es más inhumana que nunca, con menos fuerza se escuchan las voces de los geógrafos! Las escasas reflexiones que el mundo de la geografía (española en este caso, salvo honrosas excepciones), consiguen aportar al debate territorial español, al de las infraestructuras vertebradoras del país, al de la alternativa a modelos radiales de comunicaciones, a la cuestión candente de las desigualdades (un factor claramente geográfico, de posición y acumulación desequilibrada de recursos), al debate sobre el agua y a la necesidad de un reparto cooperativo, al de la bomba demográfica a la que se enfrenta España, al desenmascaramiento de los argumentos anti-inmigración, a las energías y a su uso privado, al de las nuevas bolsas de pobreza urbana, al de, incluso, las propuestas soberanistas, federalistas o recentralizadoras y a las propuestas independistas catalanas o vascas son un claro ejemplo de actitud englobada en esta idea del «mapa conservador» como hoja de ruta de la sociedad.

En España, el «mapa conservador» es dominante, ¡incluso cuando ha gobernado un partido progresista! Este mapa nos ancla en un entorno reducido, limita nuestras posibilidades, nos hace girar alrededor del mismo punto. Una obra del pintor William Kentridge es ilustrativa del «mapa conservador». Su nombre es indicativo: «Sombra sobre mapa de España (2006-2007)» (Fig.1).

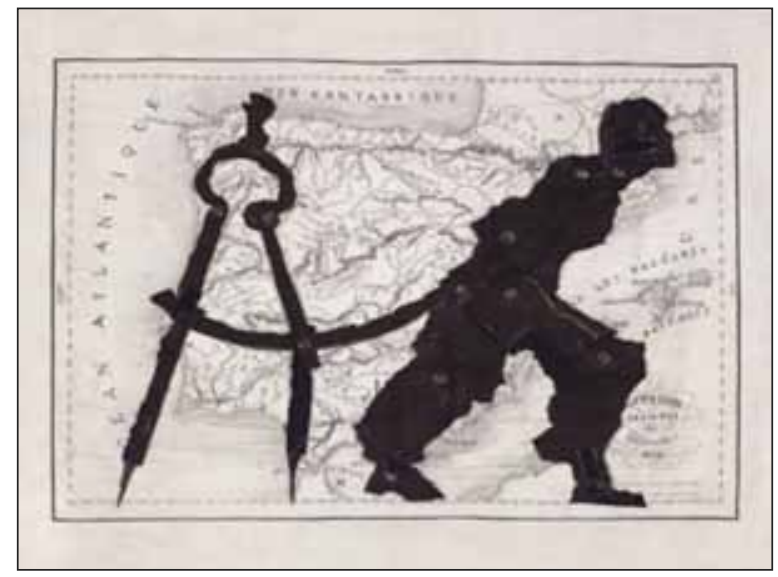

Como en esta obra de Kentridge, el «mapa conservador» nos proporciona la ilusión del movimiento, de la apertura, de la innovación, pero al cabo de un cierto tiempo no encontramos exactamente en el mismo punto de partida. Somos como esa sombra anclada al suelo por un compás que apenas nos da, pese a nuestra ilusión de autonomía, un breve espacio de movimiento, una ligerísima capacidad de acción.

Pero, ¿por qué hay que deconstruir este «mapa conservador»? Esta idea proviene, en parte, de los trabajos de J.B. Harley. En ellos, Harley abogaba por aplicar a la producción cartográfica los principios de la deconstrucción, buscando «romper el supuesto vínculo entre 
la realidad y la representación que ha dominado el pensamiento cartográfico» (Harley, 2001: 187), es decir, desenmascarar la premisa de que los mapistas, los cartógrafos, están empeñados en una incuestionable y transparentemente «científica» y «objetiva» manera de creación de conocimiento. El recurso a los métodos asistidos por ordenador no ha hecho sino incentivar esta forma de pensar que trasfiere al mapa la legitimidad (moral, social, política incluso, normativa y legal por supuesto) de una representación perfecta, veraz y real (eso sí, simplificada) de la realidad. Harley acude a la noción de «deconstrucción», muy de moda a finales de los años ochenta del siglo pasado, para quebrar, y citamos textualmente, la asumida directa ligazón entre realidad y representación. Deconstrucción significa, como señala este autor, leer los mapas «entre líneas» y descubrir los «silencios y las contradicciones» de los mismos. Por otra parte, este verbo está, simple y llanamente, cargado de capacidad transformadora, de subversión. Como ha señalado con clarividencia el filósofo Frederic Jameson (2012) en un tan breve como energético opúsculo, no hay nada más subversivo que «convertir lo habitual en algo insólito y distante». Por ello, no basta con sustituir el «mapa conservador»: es preciso desenmascararlo. Cuando alguien toma la realidad cotidiana y la convierte en un concepto histórico (es decir mudable, transformable, arruinando su supuesto carácter innato, invariable y dado) abre la puerta a nuevas experiencias y a vías alternativas. En este caso, los «mapas conservadores», tanto en su faceta ideológica como actitudinal, encuentran puntos de convergencia en el mantenimiento de lo convencional y del statu-quo. Los primeros (los conservadoramente ideologizados) revisten lo «espacial en lo cotidiano» de un halo inmutable, irreformable, absoluto. Los segundos, los adheridos mediante su actitud, prefieren no entrar a discutir lo que de convencional hay en lo territorial y vuelcan sus esfuerzos hacia otros campos menos comprometidos, agitándose eso sí en gran manera para dar la sensación de estar haciendo algo útil (sorprende el enorme despliegue técnico-informático, por ejemplo, de la geografía en los últimos años mientras su relevancia social y política es menor, hecho que Harley, en la obra citada, ya tomó en consideración para el contexto americano, cuando denunció la transformación del título de la revista The American Cartographer en Cartography and Geography Information Systems, toda una metáfora de nuestros tiempos, Harley, 2001: 186). El resultado en cualquier caso es semejante: se impone el «mapa conservador», en su doble realidad de producto y de proceso. Y la sociedad sigue la orientación que este mapa proporciona. Frederic Jameson, en la obra citada, elogia el teatro de Brecht justamente por someter a «deconstrucción» lo cotidiano. Aplicado este proceso, se hace evidente lo absurdo de la situación (y con ello, lo perturbador de tomar conciencia de ello). Y en el campo de la geografía, ¿qué hay más cotidiano y más convencional que el mapa?

\section{BERLUSCONI Y EL MAPA CONSERVADOR}

La fotografía de un político italiano, cuidadosamente escenificada, es un claro ejemplo de todo lo que hemos ido comentando hasta aquí. El 24 de octubre de 2012, Silvio Berlusconi se dirigía en video a sus seguidores para anunciarles, solemnemente, que no sería candidato en los siguientes comicios italianos ${ }^{1}$. Aunque el fondo del mensaje se ha mostrado falso (como

1 El video todavía puede verse en:

http://video.corriere.it/video-messaggio-berlusconi-faccio-passo-indietro/707b76f6-1eb8-11e2-83ec-606b68a0023b 
muestra su participación en las últimas elecciones legislativas de febrero de 2013), llamaba la atención la escenografía que envolvía su pronunciamiento. Dos grandes banderas, una italiana y otra europea (la primera ribeteada con hilos de oro, como las banderas presidenciales o, en cualquier caso, como las enseñas de categoría superior a las habituales), una lujosa y cortina de pesada tela color áureo, una silla de la que se adivina un respaldo clásico y una mesa de sobria madera oscura sobre la que se observa con facilidad... ¡ Un gran mapa del mundo! Sobre él, pero sin ocultarlo a la vista del espectador, unas cuartillas con su discurso.

¿Por qué un mapa? ¿Por qué razón Berlusconi no utilizó una clásica carpeta de cuero marrón como las que usan los notarios o los médicos y de donde extraen inmaculadas hojas en blanco para sus anotaciones? ¿Y por qué justamente ese mapa, donde se podían adivinar los diferentes estados por los colores vivos que los representan y que fragmentaban la superficie cartográfica? En principio porque tal vez sea consciente de la íntima relación entre representación cartográfica y poder: «En los retratos de los emperadores, monarcas, hombres de Estado, generales y papas, los mapas también aparecen como un resumen gráfico del poder social y territorial que se esperaba que ejercieran» (Harley, 2001: 102). Si Isabel I de Inglaterra aparece en retratos sobre un mapa, si Luis XIV, el Papa Pío IV o Napoleón son representados cerca de un plano o de un mapa, ¿por qué no un hombre que ha concentrado gran parte del poder político italiano y aspira a mantenerlo?

La cuidadosa selección de los elementos escenográficos nos da que pensar: una bandera «nacional», una bandera «transnacional» (Europa) y un mapa de estados-nación... Antes que nada, un mapa. La presencia del mapa habla por sí mismo. La vuelta de la geografía a primer plano de la existencia humana se hace evidente, la sensación de que el discurso escrito en aquellas cuartillas de Silvio Berlusconi se debía apoyar, físicamente, en una visión del mundo, en una visión espacial del mismo. ¿Cartografía retórica, se preguntaba Harley (2001:201)? Sí, pero también retórica cartográfica... Y acto seguido, de qué mapa: pues del «mapa conservador». Lo espacial vuelve, lo territorial emerge, la geografía (y su acerado instrumento de acción, la geopolítica) está de moda. Pero en gran parte esta «vuelta de la geografía» se está haciendo con el «mapa conservador» como materialización, como proceso y como fin...El antiguo primer ministro y hombre de negocios italiano parece querer transmitirnos un mensaje: sustentado por la idea del estado-nación, compartiendo protagonismo con el azul estrellado de una idea paneuropea venida a menos, quiero mostrar la vigencia del mapa, de la geografía (pero de una geografía determinada) como base del mundo. Banderas y mapas.

El mensaje de Berlusconi está a la altura de su dominio de la escenografía, de su conocimiento de la importancia de la telegenia. Embarcado en negocios televisivos, conoce bien el poder de la imagen en la sociedad actual. Berlusconi, con este escenario, da la razón a filósofos de la postmodernidad crítica como Frederic Jameson, cuando señala que nuestro tiempo se caracteriza justamente por la emergencia de las categorías espaciales y por su dominio sobre las temporales (una idea que ya defendió Michel Focault en 1967, citado por Crang 2005, cuando apuntó que la gran obsesión del siglo XIX había sido la historia, mientras que la época actual vivía la del espacio). De hecho, Jameson no duda en afirmar que «la postmodernidad puede ser caracterizada, ciertamente, por el creciente predominio de lo espacial sobre lo temporal». Nada dice Jameson sobre la orientación ideológica de esta «espacialidad» renacida, aunque añadimos nosotros que este predominio de lo espacial es un 
predominio particular y muy selectivo, por lo que sería mejor decir que, como en el caso de Berlusconi, se trata del predominio de lo espacial desde-un-punto-de-vista, desde el punto de vista del «mapa conservador», una sutil mezcla de viejas visiones territoriales y espaciales y de nuevas formas de aproximarse a la realidad capturadas hábilmente de una correcta y atenta lectura e interpretación de los tiempos actuales.

\section{ESPAÑA Y EL MAPA CONSERVADOR}

Veamos qué ocurre por ejemplo, en España (aunque no sólo en España) con el concepto territorial y político que ha marcado el devenir de los últimos, como mínimo, doscientos años de su historia, el estado-nación. La gestión reciente del «mapa conservador», especialmente por los gobiernos del Partido Popular pero también por algunos políticos socialistas, muestra rasgos básicamente postmodernos y por tanto actuales. Siguiendo a Jameson podemos identificar, al menos, dos, además de la ya comentada importancia atribuida a lo espacial (a lo espacial matizadamente y oportunamente seleccionado, queremos decir). Estas dos nuevas dimensiones postmodernas que añadir a la ya comentada son: la ficción de una apuesta por la imagen, por la idea del objeto en lugar del propio objeto y la subordinación de lo político a lo económico.

En primer lugar, el «mapa conservador» español muestra un especial cuidado en adherirse a la idea clave de que lo convencional, lo real, lo habitual, lo que vemos todos los días nos ha sido dado, es así (España es así y así es España, en un argumento circular sin salida). En este sentido, la visión que se ofrece del mapa (real en este caso) de España oculta claramente cualquier dimensión temporal y se hace así plenamente atemporal, espacial en su sentido menos rico (en su sentido de pura superficie): siempre ha existido así, como lo vemos hoy... Españoles desde Atapuerca ( $¡$ o nacionalmente catalanes desde hace mil años!). No hay discusión posible sobre la historia, sobre las Españas (algunas vencidas, como recordó Ernest Lluch en 1999), sobre las conquistas y las guerras en la península ibérica, sobre añadidos, pérdidas, mutilaciones. A un español actual, debido a este predominio del mapa intemporal, le resulta difícil entender episodios como las cruentas y terribles guerras entre Aragón y Castilla, en el siglo XIV, o el uso por el rey Felipe V del «justo derecho de conquista» (conquista de otros territorios de España) para anular fueros y libertades locales, como pasó en el siglo XVIII con la guerra de Sucesión. Las sucesivas reconfiguraciones espaciales históricas (por ejemplo el pasado «francés» de Navarra o la porción de Catalunya perdida ante Francia en 1640) es borrado cuidadosamente, aunque no todo el pasado sino especialmente aquel que está relacionado por la mutabilidad del mapa del presente (de hecho, es argumento recurrente citar la «españolidad» de Ceuta y Melilla o de Gibraltar). De esta manera, tal vez se entienda mejor la importancia de deconstruir el mapa..., de someter el espacio representado a un minucioso (y subversivo) proceso de «historización». El «mapa conservador» tiene la habilidad de llevar al paroxismo los vectores reales de la postmodernidad y de aquí su éxito.

Lógica consecuencia de este «llevar al extremo» la victoria de lo espacial es jocultar la diferencia! Jameson señala que el rasgo esencial del «modernismo» y de los clásicos modernos era la fascinación por lo «temporal» (Focault prefirió hablar de la historia) y cita las obras de grandes escritores «modernos» como Proust, Mann, Platonov o Lawrence. Y nos 
convence cuando explica que esta fascinación por lo temporal provenía del interés de estos literatos por los diferentes «ritmos» temporales que caracterizaban aquellas sociedades: ciudades rápidas y pueblos lentos, regiones avanzadas y comarcas primitivas, países capitalistas y áreas prehistóricas, sociedades secularizadas y tribus jerarquizadas y, entre medio, toda una vastedad de situaciones, de gradaciones ${ }^{2}$. La diferencia, señala Jameson, se entendía como un fenómeno temporal y esto fascinaba a los grandes escritores de la modernidad. Pues bien, hoy, el «mapa conservador» se apunta claramente a la perspectiva postmoderna olvidándose (o mejor, haciéndonos olvidar) el tiempo, la diferencia, y resaltando el triunfo total de lo espacial sobre lo temporal. A ojos del «mapa conservador», y citamos a Jameson, «lo postmoderno es lo que tenemos cuando la modernización resulta completa»: si la modernización es completa, si no hay diferencias (temporales, ni de modelo, ni de ritmo, ni de voluntades, ni de rasgos o ideas), entonces todo es igual y el espacio se convierte en el gran dominador: de aquí surge también la idea de la globalización, un solo mundo, pero con un solo modelo. El engaño está servido. De aquí que el «mapa conservador» defienda ficciones espaciales como la «unidad de mercado» (en realidad, un concepto que depende de la escala a la que se vea: ¡una unidad de mercado español podría llegar a ser una «desunión de mercado» europeo o mundial!) e incluso ideas de una cultura «común» (común a un espacio finito), «identidad compartida» (compartida por personas de un área limitada por fronteras). Las apelaciones genéricas del nacionalismo español al orgullo de «nuestra lengua» (sin especificación de cuál, en un estado donde hay, al menos, cuatro) muestra la pretensión totalizadora de la concepción espacial del «mapa conservador»: no hay diferencias, sólo hay un espacio donde sólo hay una lengua, «la nuestra». ¿No había otro signo para representar al Instituto Cervantes que la letra ñ que no existe, por ejemplo, en el catalán, que se usa poquísimo en el vasco y que algunas normativas reintegracionistas del gallego pretenden sustituir por la nh?

Pero aquí llegamos al segundo punto: en realidad, este espacio unidimensional, limitado, soberano, westfaliano, se está convirtiendo en una ficción. Siguiendo con las características de lo postmoderno citadas por Jameson, nuestra sociedad no se embelesa ya por la obra de arte, ¡sino por la idea de la obra de arte! Nos basta con eso. Estamos educados para ello, pues hemos sido adiestrados en la «colonización de la publicidad y de las imágenes». Así, viejos estados-nación como España o Italia, que en realidad están sometidos a presiones fortísimas sobre su soberanía económica, militar e incluso política (más evidentes son incluso en este último caso los ejemplos de Portugal o de Grecia) se defienden con habilidad esgrimiendo el arma por excelencia de la postmodernidad: el simulacro.

$\mathrm{El}$ «mapa conservador» realiza la misma operación que las corrientes artísticas han hecho en nuestro tiempo. La «obra de arte» ya no existe. La pintura no dispone ya de estilos. Pero ello no implica que el ciudadano no «consuma» arte. Como señala Jameson, la ausencia de pintura no implica que no existan artistas. Sólo que estos artistas producen otras cosas, de tal manera que el aficionado al arte ya no consume arte: se conforma con consumir la idea de arte. En palabras de Jameson, «lo que consumimos ya no es una entidad puramente visual o material, sino la idea de tal entidad». Y de la misma manera que los artistas ya no necesi-

2 Para Michel Focault (en Crag, 2005), estos mismos temas eran el del desarrollo y el de la suspensión, el de la crisis y el del ciclo. Temas que son superados por la tendencia «espacial» contemporánea enraizada en la simultaneidad, la yuxtaposición, el cerca y lejos, lo disperso, lo junto. 
tan crear una obra, sino la idea de la obra, muchos defensores del «mapa conservador» no necesitan que exista en todo su esplendor «su» estado-nación (abollado seriamente por la globalización, la crisis económica, la pérdida de soberanía, los procesos paneuropeos, las demandas regionalistas o nacionalistas, las presiones de los mercados, la troika, los movimientos sociales...), ¡sino sólo la idea de ese estado-nación! No es por tanto extraño que, a medida que las estructuras soberanas del estado-nación se han ido deshilachando, símbolos como las selecciones de futbol o las competiciones deportivas «nacionales» se erijan en atractivos medios de agitación, de unificación y consumo de sentimientos. Recientemente, Joan Fontcuberta (2012), refiriéndose al arte fotográfico, nos ha indicado el camino de la política actual: el artista (el político que usa el «mapa conservador» diríamos nosotros) «ya no (...) trata de producir obras, sino de prescribir sentidos», mientras se produce un cambio en la función de las imágenes en el arte (el mapa conservador en nuestro campo): «prevalece la circulación y gestión de la imagen sobre el contenido de la imagen». Prescribir sentidos, intensificar la circulación de la imagen...

Y en tercer lugar, Jameson señala que, en este olvido de las diferencias, todo tiende a igualarse, a confundirse, como se confunden política y economía. En nuestro tiempo se tiende a la «des-diferenciación» entre ambas cosas, aboliendo la autonomía de cada una de ellas. Jameson nos señala la fusión entre economía y política y su apuesta por una «desunión radical de estas dos esferas». A diferencia de lo que podría parecer, este proceso de desunión ya está sucediendo, aunque en forma, apunta, de caricatura: es muy sencillo, basta abolir una de las dos categorías para hacer triunfar a la contraria. Así, la desunión se realiza mediante la destrucción de una de ellas.

La izquierda, señala Jameson, apuesta por la sobrestimación de la política sobre la economía. Si interpretamos bien sus palabras, se trataría de apuestas poco rigurosas que vemos todos los días en nuestras calles desde el 15-M: crítica del sistema parlamentario, «fantasías de una nueva democracia universal y comunicacional a partir de Internet» o incluso antiguas visiones anarquistas de diverso tipo: todo basado en el estado, en los mecanismos del poder, en la política. Cambiemos la política y cambiaremos el mundo (sin cambiar la economía, la vieja aspiración de la socialdemocracia, señala el marxista Jameson). La derecha en cambio aniquila la política en favor de la economía. El mercado dicta las normas, los capitales señalan los límites, las decisiones dependen de los las bolsas y de los centros de capital global. Los gobiernos se pliegan a las primas de riesgo... Y las cosas se deben hacer porque sí, porque así lo exige la (difícil) situación económica a la que nos enfrentamos.

Así, se produce la victoria del «mapa conservador»: se olvidan las diferencias y se muestra esplendoroso el triunfo del espacio sobre el tiempo (triunfo real, añadimos nosotros, aunque convenientemente presentado y maquillado, seleccionando sus rasgos). Al tiempo, se ofrece a los ciudadanos el consumo de la idea de patria antes que la patria misma (en realidad irreconocible bajo su forma de estado-nación nacido en la Westfalia de 1648) y se arrincona la dimensión política oscurecida por la economía. Una tormenta perfecta para la salud democrática de los ciudadanos.

La capacidad del «mapa conservador» para perpetuarse es impresionante, pues mantiene la habilidad de aprovecharse de algunos de los rasgos más dinámicos de la postmodernidad para, aliados a los efectos de la crisis económica y social actual, al miedo, al temor y al pesimismo, producir un escenario creíble. Sólo de esta manera, el «mapa conservador» español 
puede hacer dos cosas a la vez (y no sólo dos cosas a la vez, sino dos cosas contradictorias entre sí), como atacar los intentos de otros nacionalismos de alterar las fronteras de «su» estado-nación con argumentos de superación del mito de las fronteras en una mundo globalizado pero erigir durísimas fronteras a otros procesos, como la inmigración, el libre tránsito de personas, las aspiraciones de otros, la difusión de lenguas o de culturas... En esencia, deberían ser juzgadas como contradictorios argumentos como los esgrimidos por el gobierno del Partido Popular para oponerse a la apuesta soberanista de Catalunya y su pretensión de reforzar barreras en lugares como Ceuta y Melilla. Así, el presidente Rajoy no duda en señalar (textualmente) que «levantar barreras y fronteras va contra la corriente histórica y el espíritu de la Unión Europea» (en una declaraciones el 10 de noviembre de 2012), pero al mismo tiempo el presidente de la ciudad autónoma de Melilla Juan José Imbroda no duda en declarar (también textualmente) que «el problema con la inmigración no es la cuantía, sino la sensación de que la frontera española es vulnerable y eso es un principio que España no puede consentir» (declaraciones a Europa Press de 24 de octubre de 2012). El «mapa conservador» no tiene problema alguno en señalar que las fronteras son desaconsejables siempre que sean «nuevas». Las viejas fronteras no sólo no son molestas, sino que son materia de estado. Son el termómetro, como señala Imbroda, que mide la salud del estado-nación. En este sentido, en esta contradicción de perspectivas, este juego de apertura y cierre «a la carta», esta manipulación incluso del concepto de frontera nos da pie para aplicar el principio de la deconstrucción, como señala Harley (2001: 197): «deconstruir un fragmento de texto es poner a funcionar una suerte de estrategia inversa buscando, precisamente, en todos estos detalles que se han descuidado (metáforas incidentales, pies de página, giros casuales del argumento) y que siempre y necesariamente fueron pasados por alto por los intérpretes de una tendencia más ortodoxa».

\section{FROM RACES TO SPACES: LA VENGANZA DE LA GEOGRAFÍA Y NUEVAS GEOMETRÍAS DE PODER}

Pero el «mapa conservador» está siendo retado por mapas que provienen del pasado, curiosamente. La vuelta de la geografía a primer plano de la actualidad se realiza buscando nuevas formas de entrada y sin desdeñar los viejos pasaportes, convenientemente restaurados. Tenemos dos ejemplos de ello. El primero, el informe Global Trends 2030: Alternative Worlds, que hubiera hecho las delicias de los viejos geopolíticos del siglo XIX y XX, hecho público por el National Intelligence Council (NIC) norteamericano en 2012 y el segundo, el libro de Robert Kaplan The revenge of Geography. What the map tells us about coming conflicts and the battle again fate (traducción al castellano en RBA, 2013: La venganza de la Geografía).

El informe del NIC (al que deberíamos dedicar mucha más atención de la que podemos hacer aquí) es el mejor documento reciente para valorar la vuelta de los análisis geopolíticos y geoeconómicos al escenario mundial y a las perspectivas de futuro. En la introducción del informe podemos leer: This report is intended to stimulate thinking about the rapid and vast geopolitical changes characterizing the world today and possible global trajectories during the next 15-20 years. El texto llama la atención sobre aspectos como la pérdida de hegemonías del poder mundial (pluralidad por difusión del poder), la inestabilidad demográfica 
y la plena entrada de la inmigración y de la perspectiva urbana en los análisis sociopolíticos globales, la importancia del agua, la alimentación y la energía (y sus relaciones), la trituradora mundial que puede llegar a ser una alianza tácita USA-China (con predominio del Pacífico sobre otros mares) o la aparición, y citamos casi textualmente, de una serie de protagonistas llamados nonstate world (de las megaciudades a las ONGs, de opinión pública a las coaliciones ciudadanas de clase media y de élites formadas) con los que habrá que contar y que harán que, si bien los estados-nación no desaparezcan, los países deban organizar y orquestar cada vez más coaliciones híbridas de estado y actores no estatales. Y hay un serio toque de atención al «mapa conservador»: incluso los países democráticos, enlazados tradicionalmente con los conceptos de soberanía e independencia, encontrarán difícil maniobrar con éxito en este mundo complejo y diverso. El informe, en su página 19, llama la atención sobre la adaptabilidad de los pequeños sobre los grandes países... ¿Cuántas de estas pinceladas de reflexiones geopolíticas han llegado a nuestro país? ¿Cuánta atención se dedica en los medios de comunicación, en los gabinetes de gobierno, en los círculos de poder o incluso en los departamentos universitarios? A (¿casi?) todos los gobiernos de la España democrática se les podría aplicar aquello que el precedente de este informe que comentamos («El Mundo en el Año 2000», informe presentado al presidente Carter en julio de 1981) señalaba: «A lo largo de estos años, el gobierno ha tendido a esperar que ocurriesen las crisis y sólo entonces ha reaccionado ante ellas -en vez de estudiar y analizar de entrada las cuestiones en aquellos casos en los que ciertos grupos han afrontado los problemas con visión de futuro...».

Kaplan (2012), por su parte, resucita a los viejos geopolíticos del siglo XIX y XX, el período más aplicado (y por ello dramático) del análisis territorial, militar y estratégico de la historia de la humanidad, para pedir paso en el debate mundial. Y nos muestra algunos datos interesantes. El que más nos afecta es su predicción sobre Europa y el Mediterráneo. Desterrando por completo el «mapa conservador» del señor Imbroda, Kaplan observa que en Europa, el Mediterráneo de nuevo (es decir, una vez más) debe volver a escribir su destino geopolítico y geoeconómico tradicional contra el que jamás debió revelarse y éste no es otro que el ser un conector geopolítico y geoeconómico al unir la Europa del sur con el norte de África, como ya se hizo en el antiguo mundo romano. Así, con esta visión, Imbroda y su «mapa conservador» (la frontera melillense de Imbroda es un claro ejemplo de percepción de lo que Kaplan llama «la línea divisoria entre las potencias imperialistas y sus antiguas colonias») entrarían en quiebra técnica inmediata. Cambiando la lógica de los paralelos por los meridianos, Europa encontraría un lugar en un mundo cada vez más dominado por la «alianza» (no escrita pero palpable) geoeconómica del Pacífico (los gigantes Estados UnidosChina). Kaplan muestra que la tierra del vino y de las aceitunas podría volver a constituir una comunidad económica y cultural sustentada en una de las reservas energéticas más potentes del mundo: las enormes reservas gasísticas y de petróleo del subsuelo mediterráneo. Desde Estados Unidos, el camino se vislumbra (de nuevo) claro: desarrollar proyectos meridianos, no paralelos. Es decir, actualizar las viejas ideas de conexión norte-sur que el International Bank for Reconstruction and Development (en los años sesenta del siglo pasado) impuso prácticamente al franquismo para construir la Autopista del Mediterráneo (Boira, 2002, 2010). Hoy en día, esta actualización tiene un nombre: el corredor ferroviario mediterráneo, uno de los desafíos más sólidos y formales al «mapa conservador» que jamás ha habido, no sólo por sus implicaciones locales (españolas), sino europeas e incluso mundiales. 
Alexander Gopnik, en la revista The New Yorker (29 de octubre de 2012) resumía el reto al que los geógrafos nos enfrentamos: hacer ver que la evolución de la forma de entender el mundo es la trayectoria de cuatro pasos, los que van (y en inglés, consigue un efecto de paronomasia envidiable por su concisión y poderío) entre races, faces, places y spaces (razas, caras, lugares y espacios). Cuenta Gopnik que la primera historia que escribió la Humanidad fue la historia de las razas (races), con sus mitos y dioses y su reconocimiento excluyente («nosotros» y, por tanto, «ellos»). Después, vino la historia de las caras (faces), esto es, la historia como épica de reyes y profetas, de faraones y de papas, de sultanes y de emperadores. Más tarde, nos llegó la historia de los lugares (places), con los países, las ciudades, los estados y los imperios, compuestos por gente, diferente pero igualada por su pertenencia a ese lugar. Y ahora ha llegado el turno de la historia de los espacios (spaces). ¡Qué gran resumen de la historia de la humanidad! Por eso, porque hemos llegado a la historia de los espacios (historia de la geografía y geografía de la historia) es tan importante reflexionar sobre qué entendemos por espacio. Y antes que nada, debemos preguntarnos sobre cómo entendemos este concepto. De aquí nuestra pretensión de deconstruir el «mapa conservador», este último un minucioso intento de cambiar todo para que nada cambie, al estilo gatopardiano de Lampedussa.

$\mathrm{El}$ «mapa conservador» no es sólo propio del nacionalismo español. Puede rastrearse en discursos del independentismo catalán o vasco, en todo aquel mapa que pretenda poner la frontera por encima del ser humano y de su diversidad, en todo aquel en el que la frontera adopta un valor absoluto, como el que muestran inscripciones como $i$ sacri confini della patria que se puede leer en algunas tumbas de soldados italianos muertos en la Primera Guerra Mundial en los Alpes (Boira 2008). Este valor es absoluto de acuerdo a unos objetivos determinados, mostrando en el fondo su relatividad... Cambiemos los objetivos y sencillamente cambiará la frontera.

\section{HISTORIA Y FRONTERA}

La historiadora Lia Quarleri, en un interesantísimo libro, nos muestra el episodio histórico que dio origen a la película The Mission (1986), y que ilustra perfectamente el aparente carácter «absoluto» de la frontera que en realidad es dependiente (y por ello, en realidad es un valor relativo) siempre de determinados intereses. A mitad del siglo XVIII, en las tierras que hoy conforman parte de los países de Uruguay y Argentina, se produjo un burocrático movimiento de fronteras con dramáticas repercusiones humanas. En 1750, las coronas de España y Portugal firmaron un acuerdo tras un largo período de conflictos en la zona del Río de la Plata. El tratado preveía un reacomodo de las fronteras entre ambos imperios y la cesión a Portugal de una amplia zona al este del río Uruguay. A cambio, España recibiría Colonia de Sacramento y el uso privativo del Río de la Plata. Las cortes reales española y portuguesa, a miles de millas del lugar, estaban satisfechas. Madrid conseguía desarticular el contrabando portugués de la zona, mientras Lisboa veía reconocida su expansión territorial, pese a contravenir el viejo Tratado de Tordesillas de 1494. El único problema era que la zona entregada a los lusitanos estaba ocupada por siete «reducciones» (o misiones) jesuíticoguaraníes. Estas reducciones habían sido explícitamente creadas por los españoles para hacer frente a las incursiones portuguesas y habían sido encomendadas a misioneros jesuitas. Pues bien, cuando la alta política entró en liza, Fernando VI ordenó el traslado forzoso de los gua- 
raníes residentes. Ante la resistencia de los pueblos locales a abandonar su tierra (una tierra dada por la monarquía hispánica cuando le convino), el gobernador de Buenos Aires inició una campaña bélica que llevó la guerra a la zona entre 1754 y 1756. La alteración de la frontera hispano-portuguesa no debía ser afectada por unos miles de indios guaraníes apoyados por un puñado de jesuitas españoles... Lo más paradójico es que tropas españolas y portuguesas, ejércitos de los dos grandes viejos enemigos en esa zona del mundo, se aliaron para aplastar la rebelión y desplazar la frontera a donde a ambas potencias les convenía. Sí. La frontera es inmutable, sacrosanta, definitoria sencillamente hasta que lo deja de ser. A este tipo de frontera (básica en el «mapa conservador», que la ensalza hasta el paroxismo pero que la usa a su antojo) se le puede aplicar aquello que Claude-Henri de Saint-Simon escribió sobre la Europa del siglo XV y su forma de gobierno: «ninguna institución que se base en una opinión debe durar más tiempo que ella». Esto mismo le pasa a la frontera vista desde la óptica del «mapa conservador». Defendida hasta la última gota de sangre, se olvida con rapidez (véase la frontera alpina entre Italia y Austria, protagonista de uno de los más cruentos enfrentamientos en la Primera Guerra Mundial y ahora espacio de libre tránsito de turistas aficionados a la montaña, que descansan en las viejas trincheras) cuando las circunstancias lo aconsejan.

La moraleja del episodio del Río de la Plata es muy oportuna: en un momento de gran actualidad de la geografía (recordemos el grito unánime de geography is back), debemos estar atentos a la manipulación del «mapa conservador». Sea en el siglo XVIII como en el XXI, el ser humano puede ser sacrificado, en el altar de (una) geografía, de (un) territorio, de (una) frontera, para beneficio de los poderosos quienes, a miles (o a cientos) de kilómetros de distancia de ese lugar, juegan con los mapas como con piezas inanimadas de un tablero de ajedrez. Y en las profundidades de la selva, como hoy en el corazón de nuestras ciudades, los seres humanos se ven inmersos en un diabólico proceso que relativiza su valor, que los hace dependientes de decisiones ajenas con gran repercusión territorial y espacial. Es preciso, pues, recobrar el control democrático de la geografía, el control ciudadano de los procesos territoriales, el debate político de los instrumentos de acción urbana, metropolitana y espacial.

Podemos imaginar la desolación de aquellos jesuitas que, remontando el río Paraguay, habían conseguido fundar Nuestra Señora de Loreto y San Ignacio (1610) en el Guayrá o San Ignacio Guazú (1610) y Encarnación de Itapúa (1615) en el Paraná inferior. Jesuitas que se habían enfrentado a españoles y criollos cuando éstos pretendieron transformar las misiones en reservas de mano de obra para los yerbatales y los tabacales. Estas reducciones, gracias a los jesuitas, fueron ganando en peso y dignidad, haciendo a los guaraníes responsables de su propia tierra. Desde Madrid, estos asentamientos fueron elevados a milicias del rey y armados a partir de 1647 para hacer frente a los enemigos portugueses que atravesaban esta lejana y olvidada frontera del Imperio español establecida a finales del siglo XV. Los guerreros guaraníes y sus familias, unas cien mil personas, fueron útiles a los poderosos justamente hasta 1750, cuando la «razón de Estado» se impuso. Aquella frontera tan sagrada para el Imperio y a la que se habían subordinado armas y hombres, se movía de un plumazo sin consideración a los moradores de aquellas tierras y comenzaba una guerra que, paradójicamente, aliaba a los antiguos enemigos, españoles y portugueses, contra jesuitas (expulsados de los territorios españoles por Carlos III en 1767) y guaraníes. Tras la victoria europea, todavía quedaba un último acto de indignidad... Finalizado el conflicto y tras las pérdidas humanas y mate- 
riales, el daño generado y la traición ocasionada, el tratado de 1750 entre Lisboa y Madrid fue anulado en 1761 e inmediatamente después, España y Portugal entraron en guerra.

¿Hay mejor ejemplo que esta pequeña historia de la mezcla de la dimensión local con la global, sea hoy o en el siglo XVIII? ¿Hay mejor ejemplo que nos hable del carácter inhumano al que los instrumentos de la geografía y la geopolítica pueden llegar si no se corrige su orientación? ¿Hay mejor ejemplo de lo que la manipulación de la frontera puede significar para la vida de los seres humanos?

Jugamos con fuego. La geografía ha vuelto. Pero el «mapa conservador» también, adherido. Debemos estar atentos a su juego. Y prevenir sus efectos. La historiadora Lia Quarleri nos advirtió: «bajo el absolutismo borbónico, la definición de las fronteras y de los circuitos comerciales estaba por encima de la preservación de las doctrinas o pueblos de indios». Hoy en día, se vislumbra una situación en la que, de nuevo, y ante el resurgir de la geografía, determinados intereses están por encima de la dignidad humana. Quienes nos dedicamos a la geografía «humana» deberíamos esforzarnos por evitar la «inhumanidad» creciente de la geografía que nos rodea.

\section{VI. ¿UNA ALTERNATIVA AL MAPA CONSERVADOR?}

El objetivo de este escrito no era construir, sino más bien deconstruir. Con todo, no podemos dejar de ofrecer una cierta reflexión sobre, si bien no una alternativa al «mapa conservador», sí un cuadro básico donde está alternativa debe producirse. Para arrancar, tres principios tomados de Doreen Massey $(1999,2005)$ que, llevados a la práctica, cambiarían de raíz nuestra realidad territorial:

1. Deberíamos entender el espacio como producto de interrelaciones, un espacio constituido por interacciones, que van de lo global a lo local, con lo cual, el concepto de frontera como instrumento de delimitación de políticas y de competencias afloja su férrea tiranía.

2. Deberíamos entender el espacio como la esfera de la posibilidad (y) de la existencia de la multiplicidad. El espacio es la expresión de la coexistencia de distintas trayectorias posibles. Nada pues aboca a un solo camino, a una sola trayectoria.

3. Deberíamos entender el espacio como siempre en proceso de construcción, en devenir, nunca acabado.

Massey (1999) ya apuntó las profundas consecuencias de aceptar (o no) estas proposiciones. En primer lugar, su desarrollo implicaría una visión antiesencialista. En segundo lugar, una visión auténticamente asentada sobre la pluralidad y la multiplicidad de orientaciones y posibilidades y por último, la constructividad. Así pues, interacción, multiplicidad y apertura deberían ser las bases del mapa alternativo al conservador, mapa que insiste en los aspectos justamente contrarios: un espacio como una superficie dada y finita; un espacio como un túnel de entrada, salida y un único recorrido; un espacio inmutable ajeno al tiempo (sin pasado y sin futuro). Este es el caso, por ejemplo, de un libro que desde su título muestra sin tapujos su visión de este asunto. Nos referimos al libro de Francisco Sosa Wagner y de Mercedes Fuertes (2011) de título evidente: «El estado sin territorio». El desacoplamiento de 
los dos conceptos «estado» y «territorio» es un claro ejemplo de concepción unidimensional de la forma en la que un estado se muestra (ni los gobiernos autonómicos son estado, ni los municipios o las diputaciones) y de la concepción conservadora de un territorio como simple superficie sobre la que el poder ejerce sus prerrogativas, despliega sus acciones, afirma su dominio... Y citamos textualmente a los autores cuando dicen que el Estado español «como consecuencia de unos poderes locales cada vez más fuertes (...) se está quedando sin territorio donde ejercer sus funciones. Es decir, se está quedando sin una de las claves que lo han definido tradicionalmente», para defender a posteriori la tendencia «feudalizante» de la España autonómica (por ello, se habla de «señores territoriales», entre otros conceptos que recuerdan baronías y marquesados medievales). Pero entender el territorio como espacio «superficial» es, permítasenos la broma, una auténtica superficialidad, puesto que suele ir acompañado de una visión exclusiva y excluyente de su gestión y de su concepción. En esta visión no hay principios cooperadores, soberanías compartidas, geometrías variables del poder, espacios de responsabilidad ciudadana..., todo debe responder al principio de las «muñecas rusas», que reproducen espacio, soberanía, política e incluso cultura: misma forma, mismo modelo, mismos colores que se encapsulan uno dentro de otro. Congruencia territorial al cien por cien, homogeneidad total y un único modelo de relación estado-territorio, el del estado «nacional», como recuerdan los autores. Ante esta visión, otros caminos son posibles, por ejemplo el que Painter (2008) nos muestra a través de la siguiente figura (fig.2), donde la «incongruencia» territorial entre fronteras culturales, económicas y gubernamentales puede ser uno de los retos del futuro, olvidándose de la idea de un estado como contenedor, pluscuamperfecto y perfectamente engrasado, que reproduce y es coherente en cada una y todas las dimensiones de la vida del ser humano, del ciudadano de ese estado. Si nos dirigimos a culturas cada vez más relacionadas, plurales y múltiples (incluso personales, donde el concepto de identidad es discutible y discutido), si las geografías economías responden cada vez más a principios extra-«nacionales» (como las megarregiones) o a instituciones internacionales (Unión Europea), si el gobierno del territorio se entiende como corresponsabilidad, cogestión y cooperación, la figura que reproduce Painter en su escrito debería ser el principio rector y la «incongruencia» el reto que debemos asumir.

El «mapa conservador» insiste siempre en dos viejas nociones del espacio, el espacio como distancia y como superficie. De esta forma consigue un efecto estratégico para sus fines: separa lo social de lo territorial al encapsular lo espacial en una sencilla superficie, inalterable, donde ocurren las cosas y, al mismo tiempo, pese a su retórica «geograficista», reduce lo espacial, cuando piensa en distancias, ¡ a una mera una cuestión temporal! Como señaló Massey (1984), al reducir el espacio a una sola dimensión (cuantificable, eso sí, sea la superficie o la distancia) se resta importancia a cualquier debate explícito sobre su contenido, sobre su ordenación, sobre su organización o sus organizaciones alternativas y posibles. Una cosa es «lo social»y otra «lo espacial». Como ejemplo de esta conservadora concepción espacial se debería recordar el lema que, no hace mucho, el Ministerio de Fomento (con el PSOE en el gobierno y que el PP ha respetado) hizo suyo: «Acortando distancias, acercando personas». Estas frases muestran una visión del «mapa conservador», tanto en cuanto el hecho de acortar las distancias, de acercar personas es una operación que afecta fundamentalmente a la variable temporal (se tarda menos en desplazarse sobre el espacio o se dan facilidades para el movimiento), pero sin modificar directamente la noción de espacio y la carga 


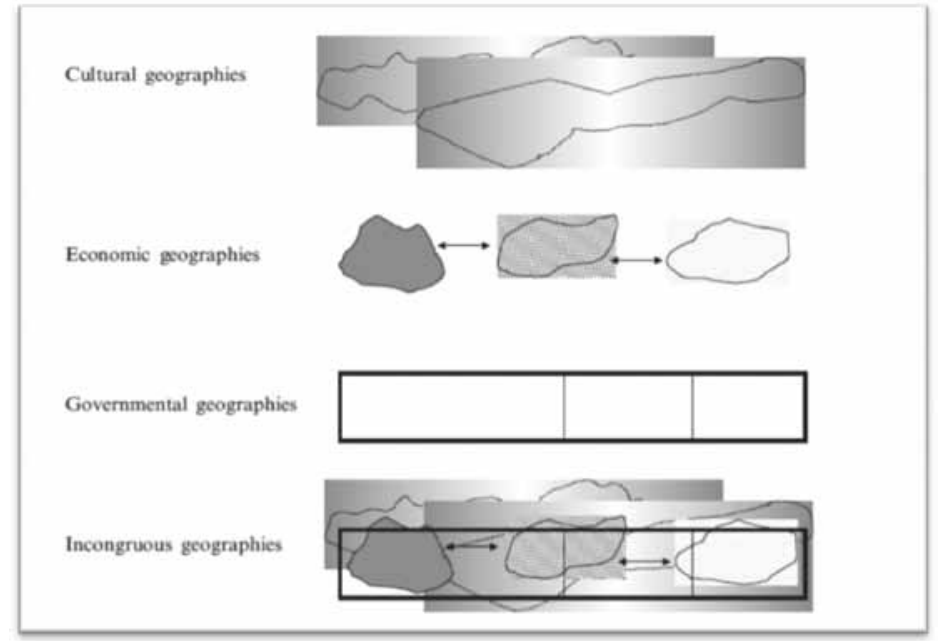

profunda del mismo, su naturaleza final. Así se puede entender que, desde esta visión, las infraestructuras de comunicación y de transporte se conciban a menudo como un instrumento al servicio del tiempo (reducir el trayecto temporal es lo esencial) y no del espacio (rearmar territorios para la producción o equilibrar un país). Los resultados, pues, de las políticas tradicionales de infraestructuras serian en realidad resultados temporales, no espaciales. La inauguración en enero de 2013 del tramo de AVE Barcelona-Figueres ha traído un nuevo lema al Ministerio de Fomento: «Para que puedas llegar». De nuevo, el espacio reducido a una cuestión de accesibilidad, de un movimiento sobre un espacio finito, sobre una superficie que hay que «vencer»...

\section{CONCLUSIÓN}

El desenmascaramiento del «mapa conservador» debe llevar a desconfiar de las visiones «espacialistas» de sus defensores, que en realidad esconden una concepción muy poco territorial y geográfica del mundo contemporáneo. Es, por decirlo así, la «agenda oculta» de este aparente triunfo de lo espacial. Pese a la aparente adscripción a lo «espacial» del «mapa conservador» y su abundante profusión de signos y símbolos (velocidad, distancia, mapa, conexión, flujos, globalización, modernización, trenes, record mundial de kilómetros de alta velocidad...), este mapa como proceso debe ser leído entre líneas (como propone para el objeto en sí mismo Harley, 2001: 188) pues oculta, al menos, una triple jugada (Massey, 2006): en primer lugar la conversión del espacio en una especie de túnel del tiempo a escala mundial, de tal manera que la globalización actual se convierte en un simple proceso temporal por el que todos los países deben pasar con el mismo objetivo, modelo y ritmo (las propuestas del Fondo Monetario Internacional recetadas para salir de la crisis van en esta 
misma dirección: no importan quién seas, de dónde vengas o a dónde vayas, cuál sea tu estado, tu contex to o tu tradición. Sólo hay una salida a la crisis, un único modelo por el que, más tarde o temprano, todos deben pasar). La multiplicidad de la geografía se reduce, así, a una unidimensionalidad temporal o en palabras de la propia Massey, «la geografía desigual del mundo se organiza eficazmente en una secuencia histórica. La geografía (...) se convierte en historia (entendida como una secuencia lineal)» (Massey, 2006). En segundo lugar, la ya comentada reducción del concepto espacial (social, polisémico) a una dimensión puramente cuantitativa, a una superficie dada, a una distancia que hay que domar, vencer, «acortar». Y, en tercer lugar, la pretensión de no unir jamás los análisis espacio-temporales a las escalas de análisis históricas. Bien está, piensa el «mapa conservador», que se analice el espacio (solo, es decir, la geografía como distancia) o que se analice el tiempo (solo, es decir, la historia como sucesión de hechos), pero jamás ambas cosas a la vez, pues entonces se desvelaría, por ejemplo, que las formas políticas de organización territorial y administrativa de los seres humanos serían en realidad «sucesos espacio-temporales», esto es, resultados una conformación determinada, mudable, alterable, reformable (prescindible incluso) en la larga secuencia de conformación de patrones territoriales e históricos de la humanidad.

Estamos en un período en el que la geografía ha vuelto. Geography is back. Pero esta vuelta de la geografía por sí sola (que jamás debió haberse ido o, mejor dicho, que jamás debió ser expulsada), sin someter a un proceso de deconstrucción sus mapas puede llevar a la más injusta producción de geografías injustas, tomando las palabras del último libro de Edward Soja (2011) o la más inhumana de las geografías humanas posibles. Justamente por su potencia, por su actualidad, por su responsabilidad, debemos «construir desmantelando» mediante el proceso de deconstruir el «mapa conservador» en el sentido que Harley (2001: 196) le otorga a ese verbo: «reinscribir y reubicar significados, acontecimientos y objetos dentro de movimientos y estructuras más amplios» y generar así un nuevo pensamiento crítico espacial al servicio del ser humano, de su dimensión social y de su bienestar global.

\section{REFERENCIAS}

BOIRA, J.V. (2002): Euram 2010. La via europea. Valencia. Tres i Quatre.

BOIRA, J.V. (2008): «La perspectiva interregional a Europa i els territoris locals. Una nova visió per a un debat renovat». En L'organització del territori. Un repte per al segle XXI. Barcelona. Fundació Universitat Catala d'Estiu-Galerada.

BOIRA, J.V. (2010): La Commonwealth catalano-valenciana. La formació de l'eix mediterrani al segle $X X$. Barcelona. Columna.

CRANG, M. (2005): «Time: Space», en Spaces of Geographical Thought (Cloke, P. y Johnston, R., Eds.). Londres, SAGE, 199-220.

FONTCUBERTA, J (2012) «Por un manifiesto fotográfico». En El arte en su destierro global. (Arnaldo, J. y Fernández del Campo, E., Eds). Madrid, Ediciones del Círculo de Bellas Artes, 89-111.

GOPNIK, A. (2012): «Faces, places, races. The renaissance of geographic history». The New Yorker. En http://www.newyorker.com/arts/critics/atlarge/2012/10/29/121029crat_ atlarge_gopnik

HARLEY, J.B. (1989): «Deconstructing the map». Cartographica, nº 2, 1-20. 
HARLEY, J.B. (2001): La nueva naturaleza de los mapas. Ensayos sobre la historia de la cartografía. México. Fondo de Cultura Económica.

JAMESON, F. (2012): El postmodernismo revisado. Madrid. Abada editores.

LEMMANN, N. (2001): «Atlas shrugs. The new geography argues that maps have shaped the world». The New Yorker.

Disponible en http://www.newyorker.com/archive/2001/04/09/010409crbo_books

LLADÓ, B. (2012): «El revés del mapa. Notes al voltant de Brian Harley i Franco Farinelli». Documents d'Anàlisi Geogràfica, vol. 58/1, 165-176.

LLUCH, E.(1999) Las Españas vencidas del siglo XVIII. Barcelona. Crítica.

KAPLAN, R. (2009): «The revenge of Geography». Foreign Policy, May-June. Disponible en http://www.colorado.edu/geography/class_homepages/geog_4712_sum09/materials/ Kaplan\%202009\%20Revenge\%20of\%20Geography.pdf

KAPLAN, R. (2012): The revenge of Geography. What the map tells us about coming conflicts and the battle again fate. Nueva York. Random House. Traducción al castellano en RBA, 2013. La venganza de la Geografía.

MASSEY, D. (1999, trad. española de 2012): «La filosofía y la política de la espacialidad: algunas consideraciones». En Doreen Massey. Un sentido global del lugar (Albet, A. y Benach, N., Eds.). Barcelona, Icaria.

MASSEY, D. (1984, trad. española de 2012): «Introducción: la geografía importa». En Doreen Massey. Un sentido global del lugar (Albet, A. y Benach, N., Eds.). Barcelona, Icaria.

MASSEY, D. (2005): For Space. Londres. SAGE.

MASSEY, D. (2006, trad. española de 2012): «Espacio, tiempo y responsabilidad política en una era de desigualdad global». En Doreen Massey. Un sentido global del lugar (Albet, A. y Benach, N., Eds.). Barcelona. Icaria.

NATIONAL INTELLIGENCE COUNCIL (2012): 2030 Global Trends: Alternative Worlds. Disponible en http:/globaltrends2030.files.wordpress.com/2012/12/global-trends2030-november2012.pdf

PAINTER, J. (2008) «Cartographic anxiety and the search of regionality». Environmental and Planning, A, vol. 40, 342-361.

QUARLERI, L. (2009): Rebelión y guerra en las fronteras del Plata. Guaranies, jesuitas e imperios coloniales. Buenos Aires. Fondo de Cultura Económica.

SAINT-SIMON, C-H. (ed. 2011): De la reorganización de la sociedad europea. Madrid. Círculo de Bellas Artes.

SOJA, E. (2014): Buscando la justicia espacial. Traducción al castellano, por Editorial Tirant Lo Blanch, Valencia.

SOSA, F. y FUENTES, M. (2011): El estado sin territorio. Cuatro relatos de la España autonómica. Madrid. Marcial Pons-Fundación Alfonso Martín Escudero.

VV.AA. (1982): El Mundo en el Año 2000. Madrid. Tecnos. 